\title{
Design of Mathematical Modelling and Control of Downdraft Biomass Gasifier
}

\author{
Vijay Daniel $\mathrm{P}^{1}$ and Sanjeevi Gandhi $\mathrm{A}^{2}$ \\ ${ }^{1}$ Electrical Sciences, Karunya University, India \\ ${ }^{2}$ Electical and Electronics Engineering \\ Karpagam College of Engineering, India \\ 1vijaydaniel@karunya.edu, ${ }^{2}$ sanjeevigandhi@gmail.com
}

\begin{abstract}
The most important parameter in Gasifiers is the need for Measurement and control in order to achieve the optimal results is the temperature under which the raw materials react. Diligent Analysis and deep understanding of the dynamic behavior of the temperature in a gasifier helps for optimal control during gasification process. This paper puts forth the idea of development of an empirical model and controller for biomass gasification process with airflow. Response of the process to the step changes applied to airflow velocity were recorded. This empirical model can be characterized through a second-order-plus-time-delay (SOPTD). On comparing the outcomes of the PID controller and manual controller, it was proved that the use PID controller improves the performance of process in terms of time domain specifications, set point tracking, and regulatory changes and also provides an optimum stability.
\end{abstract}

Keywords: Biomass gasification, airflow effect, empirical modelling, gasifier temperature control, PID controller

\section{Introduction}

Producing energy out of the decomposition of biomass (wood) under constrained supply of oxidizing agent is one of the most prominently developing non-nuclear from of energy. In this process, the gas generated from the decomposition of the biomass on refining and purification called the producer gas serves as a highly efficient fuel and can be used in a wide range of applications [1]. This form of energy is also reliable because of the low cost, affordability and availability of the raw material. The applications of the fuel produced include in high temperature fuel cells, hydrogen fuel and in production of electricity for better costs [2].There are different types of gasifying chambers for efficient production of the better quality of gas with numerical stimulation techniques and computerized controlled methods. But all the present models focus on the quality, the amount and the accuracy with which the gas is produced. These models are also focused only on the working basis of the gasifier which controls temperature, air movement rate, the volume of the oxidizing agents in the chamber, pressure and such experimental factors. But above all the experimental factors it is important to control the temperature at which the chamber is gasified or the temperature in which the oxidant is supplied inside the chamber for the efficient production of gas [3-4]. Therefore for monitoring and controlling the gasification temperature of the chamber, nowadays, industries use PID controllers [5].PID controllers are used because of their optimal tuning parameters, their compact size, implementation, structure and flexible design. The type of PI or PID controllers used depends on the type of biomass used for

Received (May 18, 2017), Review Result (October 30, 2017), Accepted (November 6, 2017) 
decomposition and gasification [6]. The process of the decomposition of biomass and gasification of the chambers is a nonlinear process. The system properties vary depending on the initial conditions of the system [7]. The classical PID controllers are not efficient in controlling the changing dynamics within the system as the initial conditions vary for onset of each new cycle of gasification which results in low performance and efficiency of gas production [8]. Therefore, a well optimized PID controller with graphical user interface has been used nowadays for providing friendly user interface on controlling the system and efficient gas production [9]. The advantage of using PID controllers is to provide better adjustments to control the changing parameters in the non-linear conditions of the gasifying system [10]. The objective of this research is to develop down graft gasifier system with efficient algorithm and merging them with PID controllers with an accurate mathematical model to control the changing dynamics of the nonlinear system which on further improvisation can be atomized.

\section{Experimental Setup}

The downdraft biomass gasifier used for the study with coconut shell as a feed material. Sub stoichiometric air quantity supplied to the downdraft biomass gasifier in the study is by means of an air blower. A rotameter placed at the supply to the gasifier measures the air flow rate of the air. The primary air is injected through the nozzles around the fringe of the throat to the gasifier and the preheated secondary air is delivered at the reactor's top. The reactor consists of two concentric shells of diameters $200 \mathrm{~mm}$ and $300 \mathrm{~mm}$ respectively, fabricated using mild steel. The annular space between shells aids passage for the preheated secondary air. The inner shell has two parts: The upper part of height $700 \mathrm{~mm}$ is cylindrical in shape while the lower part is conical with an altitude of $300 \mathrm{~mm}$. The inner shell constitutes a volume of $0.0243 \mathrm{~mm}^{3}$. The conical part is lined with fire clay of $3 \mathrm{~mm}$ thickness along with a grate attached to the bottom of it. The temperature of the hot gas from the reactor is brought down using a cooling tower and dust level in the gas is reduced with the help of cyclone separators. A bed of charcoal and rice husk aids to the removal of moisture and dust present in the gas. Three bag filters are employed to remove tar and other fine dust particles. The feed material is torched with the help of an eductor which also stabilizes the combustion within the reactor.

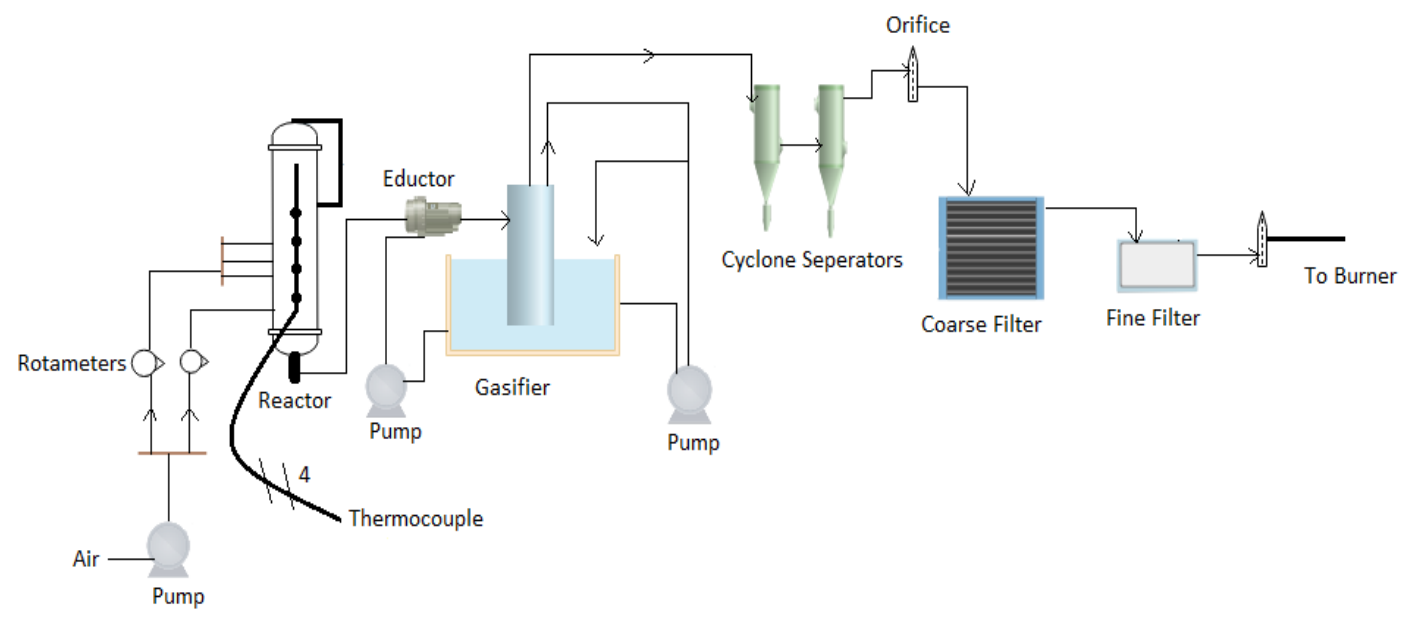

Figure 1. Experimental Configuration of the Gasifier 


\section{Modelling of the Gasification Process}

The general transfer function is developed from the block diagram in Figure 3. The corresponding general closed loop transfer function for PID control is given below: [11] [12]

$$
G_{C L}=\frac{C(S)}{R(S)}=\frac{\frac{K}{\tau_{I} \tau_{1} \tau_{2}}\left(1+\tau_{I} S+\tau_{I} \tau_{D} S^{2}\right)}{S^{3} \frac{\tau_{I}+\tau_{1}+K \tau_{D}}{\tau_{I} \tau_{2}} S^{2}+\frac{1+K}{\tau_{1} \tau_{2}} S+\frac{K}{\tau_{I} \tau_{1} \tau_{2}}}
$$

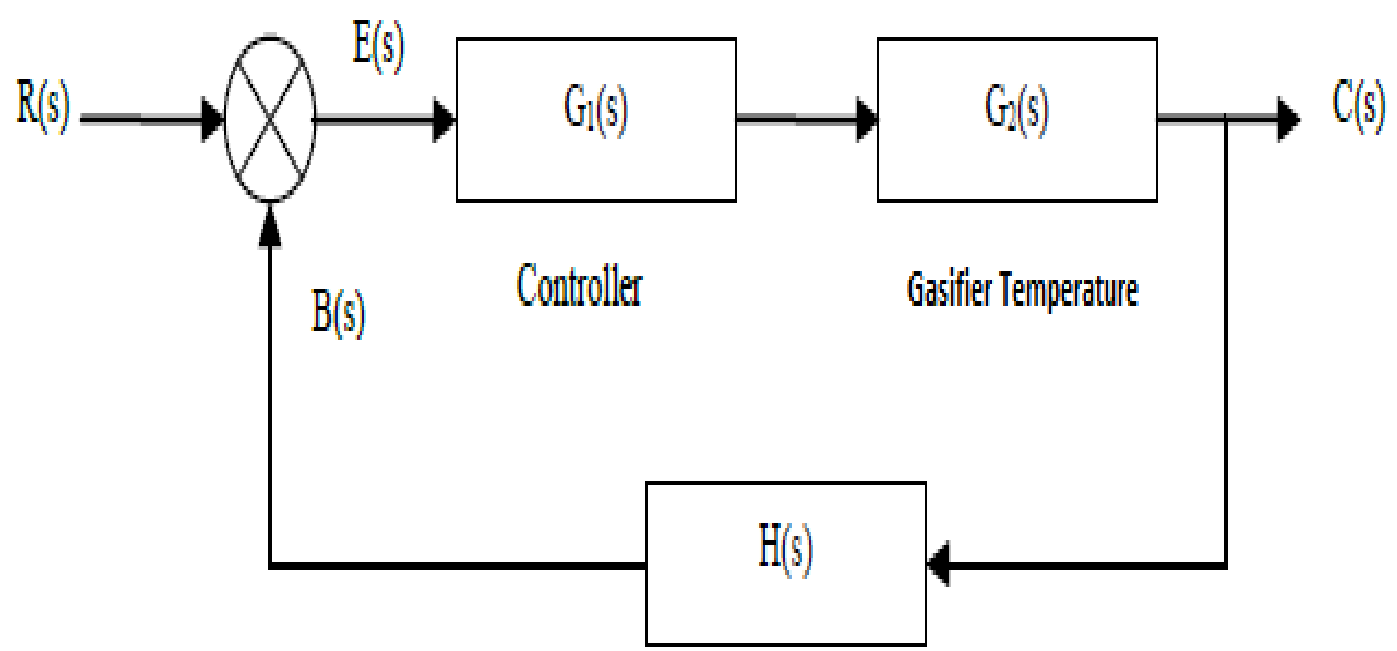

Figure 2. General Block Diagram for Gasifier Temperature Control

The closed loop response is obtained using the controller parameters. The corresponding parameters lead to the equation for $\mathrm{G} 1$ below:

$$
\begin{aligned}
& G_{1}(S)=K_{C}\left(1+\frac{1}{\tau_{T} S}+\tau_{D} S\right) \\
& G_{2}(S)=G p(S)
\end{aligned}
$$

The empirical model is developed using experimental data from the closed loop system. The closed loop identification is conducted under PID control [11-12]. The measurements taken at the drying, pyrolysis, combustion and reduction zones are identified as T1, T2, T3 and T4 respectively. The model is developed based on the closed loop step response data on the combustion zone temperature (T3). 


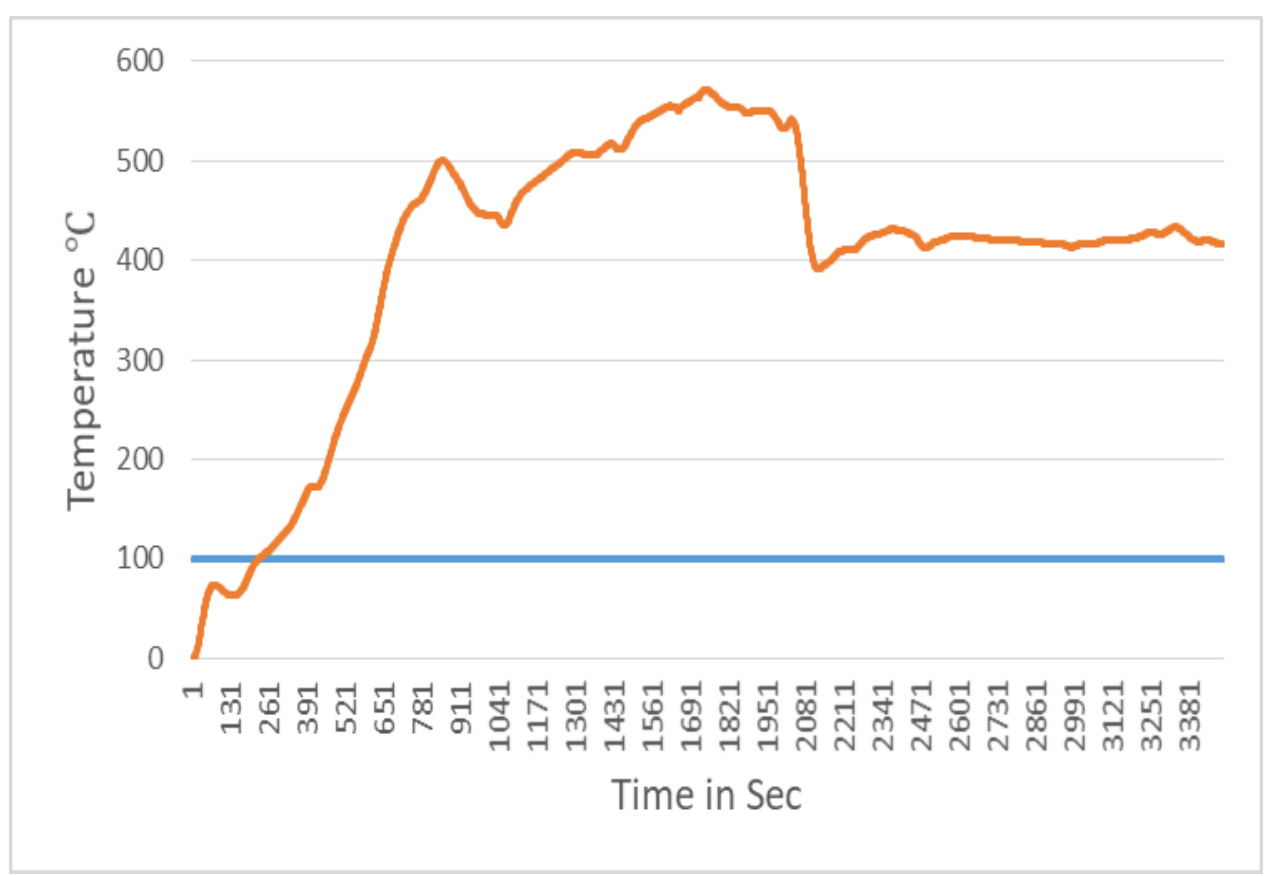

Figure 3. Transient Response for Combustion Zone Temperature

Figure 3 shows the combustion zone temperature profile in the gasifier operated under PID control. This figure represents the first process, that is, the step change in gasifier temperature from $55^{\circ} \mathrm{C}$ to $420^{\circ} \mathrm{C}$. The approximate model is developed using a second order system plus time delay.

$$
\begin{aligned}
& K=\frac{\Delta \text { Output }}{\Delta \text { Input }}=\frac{420-52}{100-50}=\frac{368}{50}=7.36 \\
& \text { OS }=\frac{a(\text { Amplitude of Ossillation })}{b(\text { Steady syate Value })}=\frac{147}{420}=0.35 \\
& \zeta=\sqrt{\frac{(\ln O S)^{2}}{\pi^{2}+(\ln O S)^{2}}}=0.3169 \\
& \tau=\frac{t_{p} \sqrt{1-\zeta^{2}}}{\pi}=\frac{1760 \sqrt{1-\zeta^{2}}}{\pi}=531.35
\end{aligned}
$$

Thus, substituting the values for $\mathrm{K}, \theta$ (estimation from graph), $\tau$ and $\zeta$ into Equation 4 gave the following:

$$
\begin{aligned}
G_{p}(s) & =\frac{K e^{-\theta s}}{\tau^{2} s^{2}+2 \zeta \tau s+1} \\
G_{p}(s) & =\frac{7.36 e^{-10 s}}{531.35^{2} s^{2}+2(0.3169)(531.35) s+1} \\
& =\frac{7.36 e^{-10 s}}{282279 s^{2}+336.76963 s+1}
\end{aligned}
$$

Hence the final transfer faction for the given system is obtained. 


\section{PID Controller for Biomass Downdraft Gasifier}

Proportional-Integral-Derivative (PID) algorithm is widely used in process industry currently. Process like heating and cooling systems, fluid level monitoring, flow control and pressure control often use PID to control. PID controller is not an adaptive controller, hence the controller has to be tuned frequently and whenever load changes. Auto- tuning of these controllers becomes difficult for complex systems [13]. A standard method of setting the parameters is through the use of Ziegler-Nichols' tuning rules [14] [15].

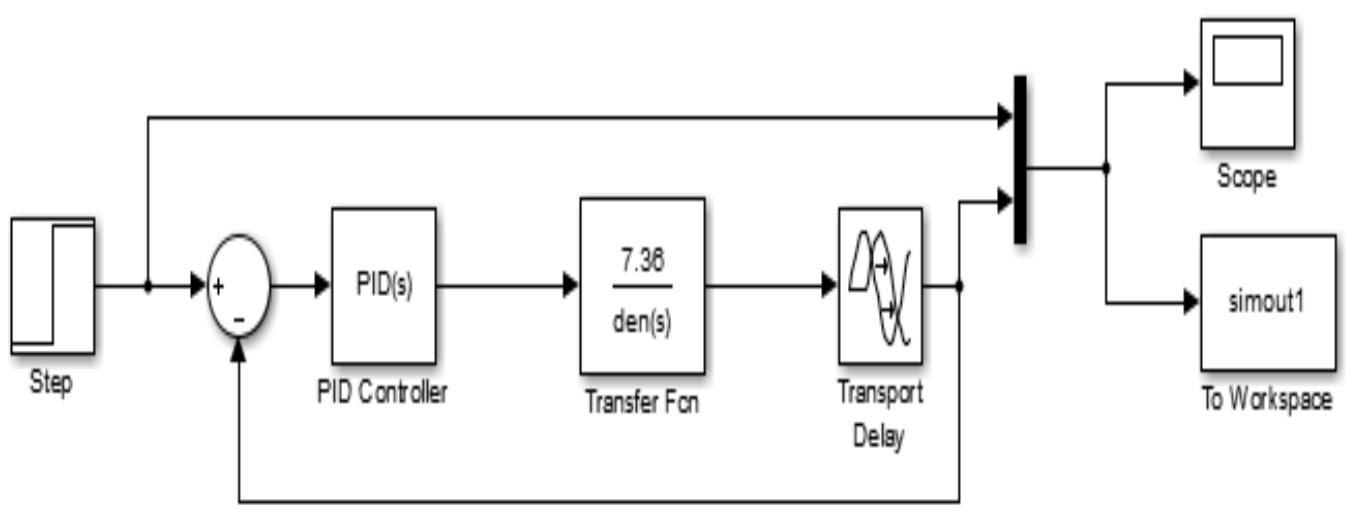

Figure 4. PID Controller for Downdraft Gasifier

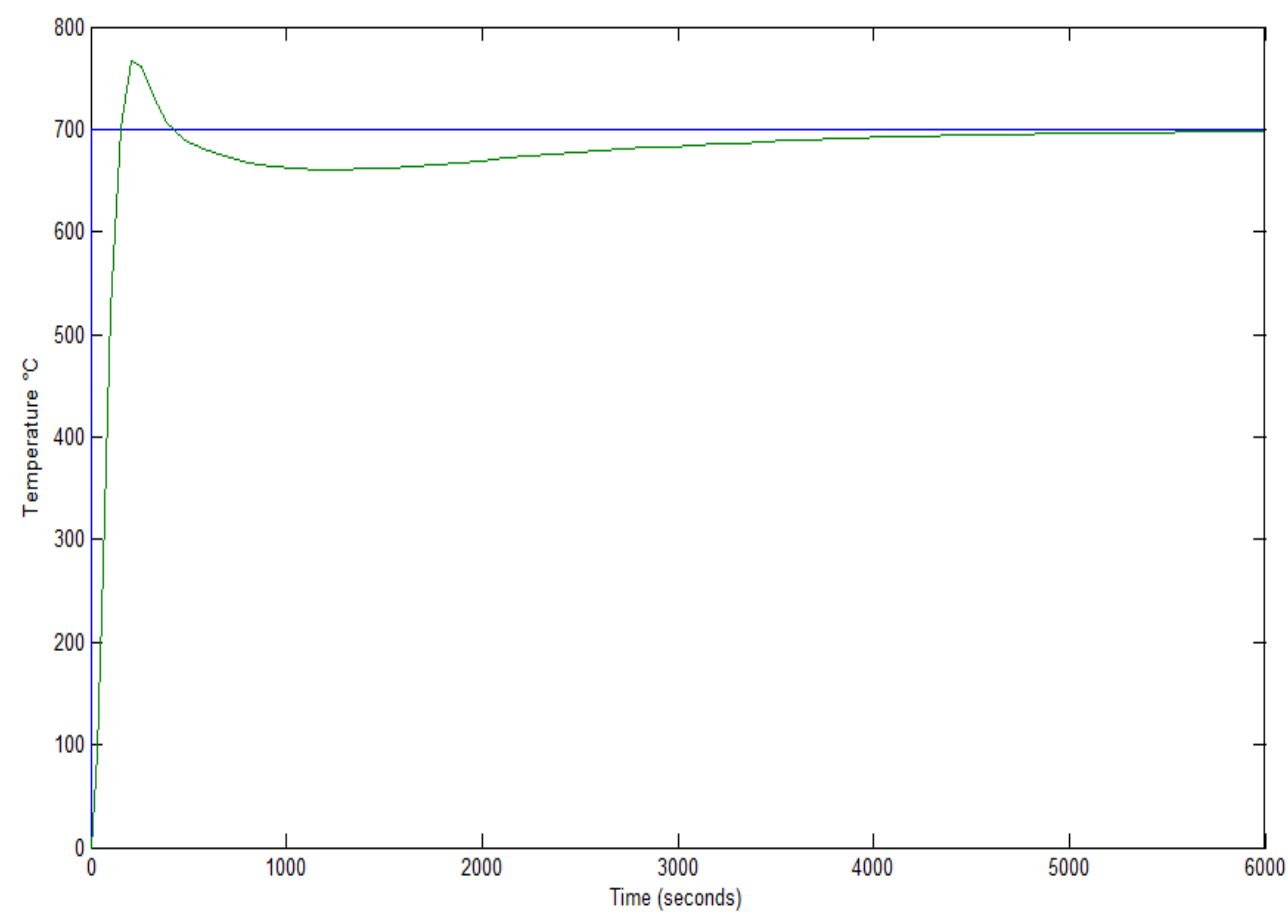

Figure 5. PID Controller Response with Set Point $=700^{\circ} \mathrm{C}$ 


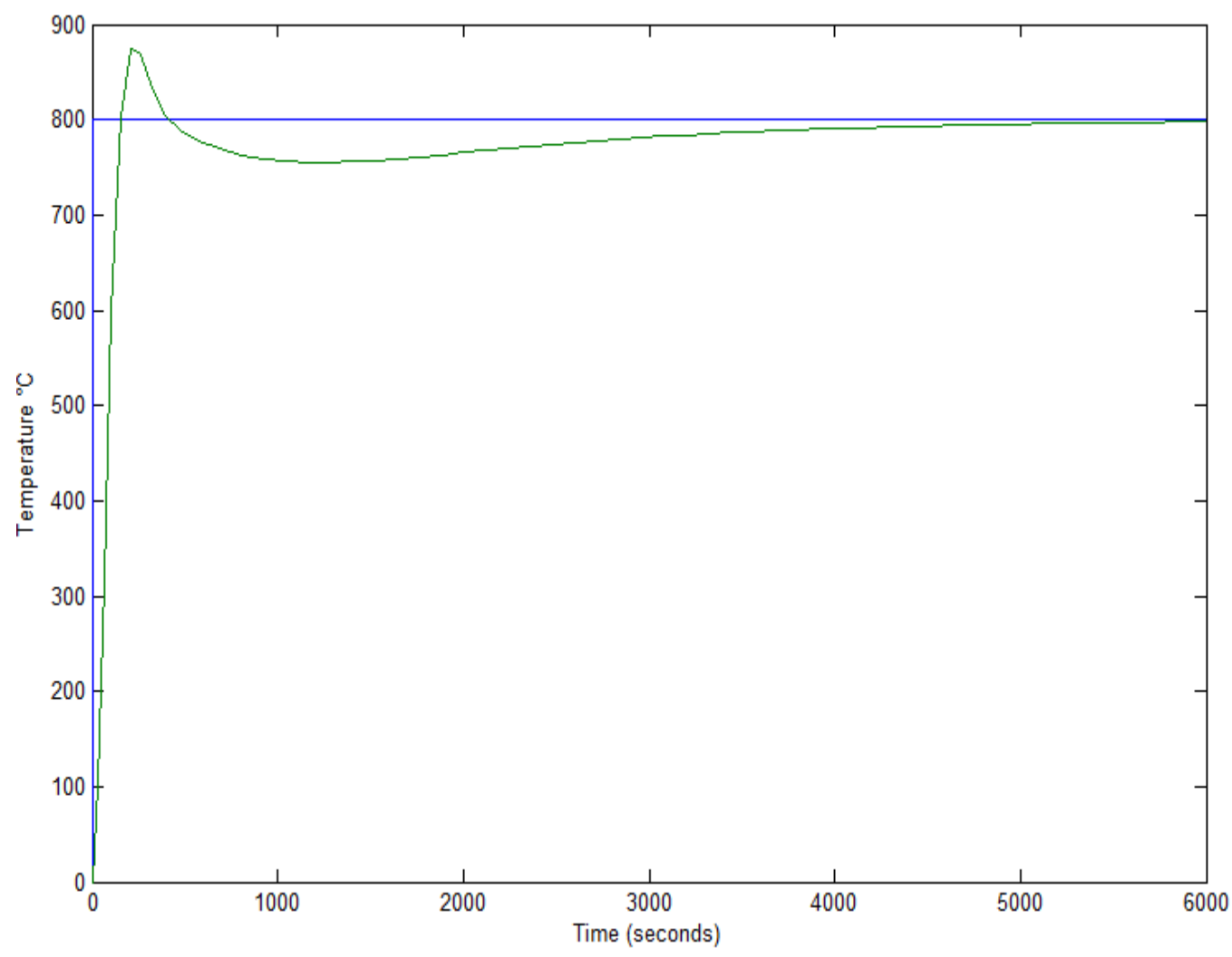

Figure 6. PID Controller Response with Set Point $=800^{\circ} \mathrm{C}$

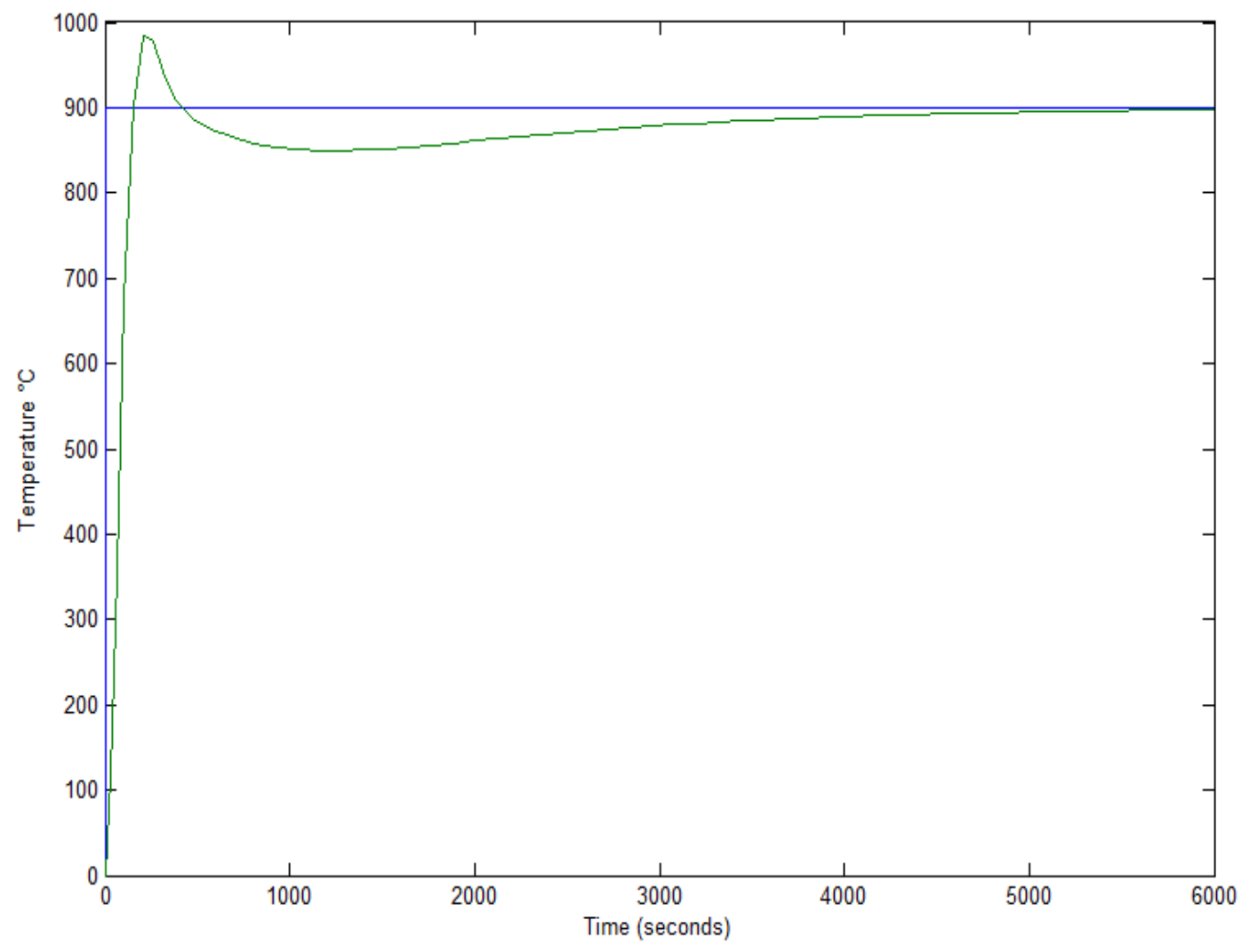

Figure 7. PID Controller Response with Set Point $=900^{\circ} \mathrm{C}$ 


\section{Results and Comparisons}

The PID controller results were compared with manual control results. The settling time taken for the downdraft biomass gasifier is shown in Table 1 for the following set points $700^{\circ} \mathrm{C}, 800^{\circ} \mathrm{C}$ and $900^{\circ} \mathrm{C}$.

\section{Table 1. Table Label Comparison of Controllers in Temperature Process}

\begin{tabular}{|c|c|c|}
\hline \multirow{2}{*}{$\begin{array}{c}\text { Set Point } \\
\left({ }^{\circ} \mathrm{C}\right)\end{array}$} & \multicolumn{2}{|c|}{ Settling Time (Minutes) } \\
\cline { 2 - 3 } & Manual Control & PID control \\
\hline 700 & 120 & 700 \\
\hline 800 & 130 & 800 \\
\hline 900 & 140 & 900 \\
\hline
\end{tabular}

From the experimental study we observe that the time taken for manual control is high compared to the PID controller. Therefore, by implementing PID controller the performance of the system will improve in terms of settling time.

\section{Conclusion}

Open loop identification is studied using experimental data on the gasification process and a static model for the biomass downdraft gasifier has been developed from the experimental data of the plant and the developed model is used to tune the PID controller. Both manual and PID controllers were tested with the step input and PID control is proved to have less overshoot and settling time during the temperature control process which proves that PID gives better performance for the control of temperature in biomass gasification process. For improving the performance, advanced control techniques are to be considered for the future work.

\section{References}

[1] K. Jaojaruek, S. Jarungthammachote, M.K.B. Gratuito, H. Wongsuwan and S. Homhual, "Experimental, "study of wood downdraft gasification for an improved producer gas quality through an innovative twostage air and premixed air/gas supply approach”, Bioresour Technology, vol. 102, no. 7, (2011), pp. 4834-40.

[2] A. Jain and J. Goss, "Determination of reactor scaling factors for throatless rice husk gasifier", Biomass and Bioenergy, vol. 18, (2000), pp. 249-256.

[3] B.V. Babu and P.N. Sheth, "Modeling and simulation of downdraft biomass gasifier", In: Proceedings of International Symposium \& 57th Annual Session of IIChE in association with AIChE (CHEMCON 2004), Mumbai, (2004).

[4] R. Scharler and I. Obernberger, "Numerical modelling of biomass grate furnaces", Proc. of the 5th European Conference on Industrial Furnaces and Boilers,' 2000, Porto (Portugal), ISBN-972-8034-04-0, INFUB, Rio Tinto, Portugal.

[5] C.R. Altafini, P. Wander and R. Barreto, "Prediction of the working parameters of a wood waste gasifier through an equilibrium model", Energy Conversion and Management, vol. 44, (2003), pp. 2763-2777.

[6] M. J. Er, and Y. Lei, "Hybrid Fuzzy Proportional-Integral Plus Conventional Derivative Control of Linear and Nonlinear Systems", IEEE Transactions on Industrial Electronics, vol. 48, no. 6, (2001), pp. 1109-1117.

[7] J. Jantzen, "Tuning of Fuzzy PID controllers", Den-mark.Tech. Report no. 98-H 871(fpid), (1998), pp. $1-22$.

[8] G.P. Liu, R. Dixon and S. Daley, "Multi-objective optimal-tuning proportional-integral controller design for the Alstom gasifier problem", Proceedings of the IMechE Part I Journal of Systems and Control Engineering, vol. 214, no. 6, (2000), pp. 395-404.

[9] C. Sagues, Garcia, P-Bacaicoa and S. Serrano, "Automatic control of biomass gasifiers using fuzzy inference system”, Bioresource Technology, (2007), pp.845-855. 
[10] C.P. Willam, "Fuzzy Logic and Real Time Applications", New Generation Publishers, Ibadan, Nigeria, (2009).

[11] N. Syafikah M. Shahapuzi, F. S. Taip, N. Ab. Aziz and A. Ahmedov, "Empirical Modelling of the Effect of Airflow on Oven Temperature Control in Cake Baking", Journal of Engineering Science, vol. 11, (2015), pp. 49-58.

[12] R. Ramachandran, S. Lakshminarayanan and G. P. Rangaiah, "Process identification using open-loop and closed-loop step responses”, J. Inst. Eng., vol. 45, no. 6, (2005), pp. 1-13.

[13] L. Chen, J. Li b and D. Ruifeng, "Identification for the second-order systems based on the step response", Mathematical and Computer Modelling, vol. 53, (2011), pp. 1074-1083

[14] E. Prempain, I. Postlethwaite and X. Sun, "robust control of the gasifier using a mixed sensitivity h1 approach", Proceedings of the IMechE Part I Journal of Systems and Control Engineering, vol. 214, no. 6, (2000), pp. 415-426.

[15] J.G. Ziegler and N.B. Nichols, "Optimum setting for automatic controllers", Trans. ASME, vol. 64, (1942), pp. 759-768.

[16] V. Chopra, S. K. Singla and L. Dewan, "Comparative Analysis of Tuning a PID Controller using Intelligent Methods", Acta Polytechnica Hungarica, vol. 11, no. 8, (2014).

[17] D. Driankov, H. Hellendoorn and M. Reinfrank, "An Introduction to Fuzzy Control”, Narosa Publishing House, New Delhi, (1996).

[18] R. Ronald, Yagner, D. Dimiter and Filer, "Essentials of Fuzzy Modeling and Control", John Wiley and Sons Inc, (2002).

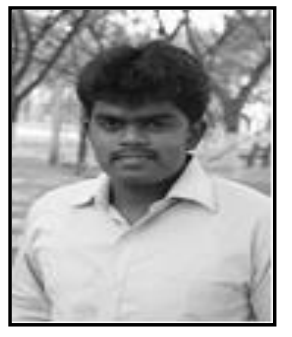

P. Vijay Daniel, he was born in Tirunelveli, India, in 1989. $\mathrm{He}$ received the B.E. degree in Electronics and Instrumentation engineering from Karunya University, Coimabatore, India, in 2010, M.E. degree in Applied Electronics from Velammal Engineering College, Chennai, India in 2012 and pursuing Ph.D. degree in Instrumentation engineering from Karunya University, Coimbatore, India. $\mathrm{He}$ is an assistant professor at Karunya University, Coimbatore, India. His research interests include Artificial Intelligence and Industrial Process Modeling \& Control.

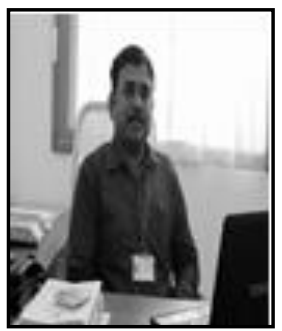

A. Sanjeevi Gandhi, he was born in Dindigul, India, in 1978. $\mathrm{He}$ received the B.E. degree in Electronics and Instrumentation engineering from Madurai Kamaraj University, Madurai, India, in 2002, M.Tech. degree in Control and Instrumentation from Karunya University, Coimbatore, India in 2006 and Ph.D. degree in Electrical engineering from Anna University, Chennai, India, in 2013.

He has a wide Technical and teaching experience of 13 years. In 2006, he joined the Department of Instrumentation and control Engineering, R.V.S College of Engineering and Technology, Dindigul, as a Lecturer, and in 2008, he moved to Sri Ramakrishna Engineering College, Coimbatore. Since June 2011, he has been with the Department of Electronics and Instrumentation Engineering, Karunya University, as an Assistant Professor.

His current research interests include Industrial Process Control, Process Control Area Networks, Biomedical Instrumentation, Industrial Process Modeling \& Control, and wireless Instrumentation system design.

He has guided several UG/PG projects and Ph.D scholars. He has published more than 50 papers in International Conferences 
and International Journals. Few of his paper were published in Inderscience Journals and other referred journals.

$\mathrm{He}$ is involved in various research activities like, Industrial Waste Water Treatment, Design and Development of Healthcare Instruments and Online Color Monitoring in Textile Waste Water. $\mathrm{He}$ is a Life Member of the Indian Society for Technical Education (ISTE), the System Society of India. 
International Journal of Control and Automation

Vol. 10, No. 11 (2017) 